\section{(A) Check for updates}

Cite this: Dalton Trans., 2018, 47 14085

Received 25th July 2018

Accepted 14th September 2018

DOI: $10.1039 / \mathrm{c} 8 \mathrm{dt} 03034 \mathrm{k}$

rsc.li/dalton

\title{
Mechanisms of the polyol reduction of copper(II) salts depending on the anion type and diol chain length $\uparrow$
}

\author{
Johannes Teichert, ${ }^{a}$ Thomas Doert (D) a and Michael Ruck (D)*a,b
}

\begin{abstract}
The mechanisms of the polyol reduction of copper(II) compounds were investigated by various systematic experiments. The course of the reduction in ethylene glycol strongly depends on the anion present in solution. Elemental copper can only be obtained in high yields starting from $\mathrm{Cu}\left(\mathrm{NO}_{3}\right)_{2}, \mathrm{Cu}(\mathrm{OAc})_{2}$, or $\mathrm{Cu}(\mathrm{OH})_{2}$; but not from $\mathrm{CuCl}_{2}$ or $\mathrm{CuSO}_{4}$. Intermediate compounds were observed, namely $\mathrm{Cu}_{2} \mathrm{O}$, and the alkoxide compounds $\mathrm{Cu}\left(\mathrm{C}_{2} \mathrm{H}_{4} \mathrm{O}_{2}\right)$ and $\mathrm{Cu}_{3}(\mathrm{OAc})_{2}\left(\mathrm{C}_{2} \mathrm{H}_{4} \mathrm{O}_{2}\right)_{2}$. $\mathrm{Cu}_{3}(\mathrm{OAc})_{2}\left(\mathrm{C}_{2} \mathrm{H}_{4} \mathrm{O}_{2}\right)_{2}$ was characterised by single-crystal $\mathrm{X}$-ray diffraction. It is a $2 \mathrm{D}$ coordination polymer with bridging bidentate acetate and bidentate deprotonated EG ligands leading to vertex- and edge-linked $\mathrm{CuO}_{5}$ polyhedra. Alkoxide compounds were also detected for higher glycol ethers. With growing glycol ether chain length the stability of alkoxide intermediates decreases, enhancing the stability range of $\mathrm{Cu}_{2} \mathrm{O}$. Because the majority of copper species is precipitated as copper(॥) alkoxide compounds or $\mathrm{Cu}_{2} \mathrm{O}$ before the reduction to elemental copper occurs, only few nuclei are formed in solution leading to microparticles instead of nanoparticles. Much smaller but strongly agglomerated particles were observed under alkaline reaction conditions.
\end{abstract}

\section{Introduction}

Polyalcohols (polyols) can act as mild reducing agents for many metal cations, yielding metallic micro- or nanoparticles from easily available metal salts. This so-called polyol process has been known for over three decades and was successfully applied to produce a variety of mono- and multimetallic materials. ${ }^{1-3}$ In these reactions, the polyol normally acts as both solvent and reducing agent. Moreover, as a surface-active substance, it can also attach to the formed particles and affect the product's particle size and morphology. ${ }^{4}$ Polyols such as ethylene glycol (EG) have good chelating properties for metal cations, which compensate the lower polarity compared to water, and therefore the solvation behaviour of metal salts in water and polyols is quite similar. ${ }^{4}$ Applying polyols as highboiling reaction media allows synthesis temperatures up to $320{ }^{\circ} \mathrm{C}$ facilitating the formation of crystalline nanoparticles without post-treatment. ${ }^{4}$

\footnotetext{
${ }^{a}$ Faculty of Chemistry and Food Chemistry, Technische Universität Dresden, 01062 Dresden, Germany. E-mail: michael.ruck@tu-dresden.de

${ }^{b}$ Max Planck Institute for Chemical Physics of Solids, Nöthnitzer Str. 40, 01187 Dresden, Germany

$\dagger$ Electronic supplementary information (ESI) available: PXRD patterns and IR spectra of the solid reaction products, DTA-TG measurements and magnetic susceptibility data of alkoxide compounds. CCDC 1857785. For ESI and crystallographic data in CIF or other electronic format see DOI: 10.1039/c8dt03034k
}

The redox potential of a polyol decreases with rising temperature. ${ }^{5,6}$ While noble metal ions are reduced at comparatively low temperatures, even at room temperature in the case of $\mathrm{Pd}^{2+}, 7$ the reduction of less noble metals cations such as $\mathrm{Co}^{2+}$, $\mathrm{Ni}^{2+}$, or $\mathrm{Cu}^{2+}$ requires higher temperatures. For a given temperature the redox potential increases with increasing chain length of the polyol. ${ }^{8}$ At higher temperature the chelating properties of polyols have to be considered when planning a reduction reaction. Coordination compounds with polyol ligands that might represent intermediate species in the polyol process have been crystallised for several of the less-noble metals. During the reduction of $\mathrm{Co}(\mathrm{OH})_{2}$ or $\mathrm{Ni}(\mathrm{OH})_{2}$ in EG a solid phase precipitates before the reduction to the respective metals occurs. ${ }^{9}$ This solid is in equilibrium with solvated $\mathrm{M}^{2+}$ ions and is regarded as a metal reservoir governing the nucleation and growth of the final particles. Systematic reduction experiments of cobalt(II) salts in EG revealed the importance of the type of anion and the deprotonation of the polyol for the progress of the reduction reaction. ${ }^{10,11}$

Like cobalt and nickel, copper particles can be obtained in polyols at elevated temperature. Copper and copper oxide nanomaterials, as cheap alternatives to precious metals, have found wide attention with respect to their potential application in catalysis, photovoltaics, and optics in the last years. ${ }^{12}$ As copper(I) is fairly stable, its emergence in the course of the reaction is not unexpected: $\mathrm{Cu}_{2} \mathrm{O}$ precipitates, e.g., as an intermediate when $\mathrm{CuO}^{13}$, or $\mathrm{CuSO}_{4}$ and 3 eq. of $\mathrm{NaOH}^{14}$ are 
heated in EG. Increasing the temperature leads to the formation of the final $\mathrm{Cu}$ particles. A solid $\mathrm{Cu}-\mathrm{EG}$ compound similar to the Co-EG and Ni-EG complexes was described in the literature. ${ }^{15}$ By heating copper acetate in diethylene glycol (DEG) a Cu-DEG compound was obtained. ${ }^{16}$ However, these compounds were not structurally characterised.

The knowledge about copper(II) species and their coordination modes in polyols is fragmentary. It was shown that the Jahn-Teller distorted tris-chelated complex $\left[\mathrm{Cu}(\mathrm{EG})_{3}\right]^{2+}$ is formed in a solution of $\mathrm{Cu}\left(\mathrm{CF}_{3} \mathrm{SO}_{3}\right)_{2}$ in EG. ${ }^{17}$ Chloride anions have a higher coordinating affinity towards copper(II) than triflate anions, which is consistent with DFT calculations indicating the formation of the complex $\left[\mathrm{CuCl}_{2}(\mathrm{EG})_{2}\right]$ instead of $\left[\mathrm{Cu}(\mathrm{EG})_{3}\right]^{2+} \cdot{ }^{18}$ The coordination ability of other anions has not been considered yet.

To establish a general understanding of the coordination and reduction behaviour of copper(II) in polyols, we carried out a series of systematic experiments. Several copper(II) precursor salts were reacted in EG, DEG, triethylene glycol (TrEG), and tetraethylene glycol (TEG) at different temperatures. Solid reaction intermediates were isolated and structurally characterised.

\section{Results and discussion}

\section{Reduction of copper(II) in ethylene glycol}

The following reduction potentials, which are only valid for aqueous solutions, have to be considered for the reduction of $\mathrm{Cu}^{2+}$ to $\mathrm{Cu}^{0} .{ }^{19}$ Reduction potentials of noble metal cations were found to follow the same order in EG and water. ${ }^{5,6}$ It is reasonable to assume that the order is also the same for the potentials considered here.

$$
\begin{gathered}
\mathrm{Cu}^{2+}+2 \mathrm{e}^{-} \rightarrow \mathrm{Cu} \quad E^{\circ}=+0.34 \mathrm{~V} \\
\mathrm{Cu}^{2+}+\mathrm{e}^{-} \rightarrow \mathrm{Cu}^{+} \quad E^{\circ}=+0.15 \mathrm{~V} \\
\mathrm{Cu}^{+}+\mathrm{e}^{-} \rightarrow \mathrm{Cu}^{0} \quad E^{\circ}=+0.52 \mathrm{~V} \\
\mathrm{Cu}_{2} \mathrm{O}+\mathrm{H}_{2} \mathrm{O}+2 \mathrm{e}^{-} \rightarrow 2 \mathrm{Cu}^{0}+2 \mathrm{OH}^{-} \quad E^{\circ}=-0.36 \mathrm{~V}
\end{gathered}
$$

As reported before, ${ }^{20}$ the reduction of $\mathrm{Cu}^{2+}$ ions to $\mathrm{Cu}^{0}$ by polyols proceeds not in one step according to (1), but in two. Initially $\mathrm{Cu}^{2+}$ is reduced to $\mathrm{Cu}^{+}(2)$. Although $\mathrm{Cu}^{+}$ions should be unstable and readily react to $\mathrm{Cu}^{0}$ according to the more positive standard potential (3), insoluble $\mathrm{Cu}_{2} \mathrm{O}$ immediately precipitates from the reaction solution. $\mathrm{Cu}_{2} \mathrm{O}$ has a more negative reduction potential (4) and gets reduced to $\mathrm{Cu}^{0}$ at a higher temperature.

The reflux temperature which can be reached for a given reaction mixture strongly depends on the water content. Polyols are hygroscopic and therefore contain a small amount of water. In this study the water content was kept low by using freshly supplied polyols. Water was also introduced by the hydrated copper salts that were used as starting materials. When 5 vol\% of water were added to reaction mixtures of EG and suitable copper(II) compounds (e.g. acetate and hydrox- ide), the boiling point dropped to $c a .160^{\circ} \mathrm{C}$ and no elemental copper was obtained under reflux conditions. However, microwave-assisted heating of mixtures in a closed vessel to $210{ }^{\circ} \mathrm{C}$ led to the formation of elemental copper. Hence, a small quantity of water does not change the general reduction behaviour but limits the boiling temperature. The water content has to be kept low to enable a complete reduction to elemental copper under ordinary reflux conditions.

The reduction of copper(II) precursor salts in EG was monitored at different temperatures. It was observed, that the anion of the copper salt has a major influence on the reduction reaction. The reduction of $\mathrm{Cu}^{2+}$ to $\mathrm{Cu}^{0}$ does not proceed when starting from copper(II) chloride. Reacting $\mathrm{CuCl}_{2}$ in EG for $2 \mathrm{~h}$ at $210{ }^{\circ} \mathrm{C}$ yielded no metallic copper but a clear green solution. This can be explained by the coordination affinity of chloride ligands towards the $\mathrm{Cu}^{2+}$ ion, which leads to the formation of solution species like $\left[\mathrm{CuCl}_{2}(\mathrm{EG})_{2}\right]{ }^{18}$ This comparatively stable complex has a lower reduction potential than $\left[\mathrm{Cu}(\mathrm{EG})_{3}\right]^{2+}$, which prevents the reduction of $\mathrm{Cu}^{2+}$ to metallic copper at the given temperature. A decreasing reduction potential with increasing chloride concentration is known from copper chloride complexes in aqueous solution. ${ }^{21}$ Although elemental copper could not be produced, $\mathrm{CuCl}$ was obtained by reacting $\mathrm{CuCl}_{2}$ in DEG at $240{ }^{\circ} \mathrm{C}$ and TrEG at $280{ }^{\circ} \mathrm{C}$, respectively. Powder X-ray diffraction (PXRD) showed no other crystalline phases. The light green solution turns dark greenish-brown upon heating, and above $220^{\circ} \mathrm{C}$ it abruptly turns into a white suspension of $\mathrm{CuCl}$.

Copper(II) sulfate can be transformed to elemental copper by refluxing in EG at $210{ }^{\circ} \mathrm{C}$. Copper was obtained only in low yields (max. 40\%), and a small amount of $\mathrm{Cu}_{2} \mathrm{O}$ was observed as a byproduct even after refluxing for $60 \mathrm{~min}$ (Fig. S1 $\dagger$ ). Conducting the reaction at $240{ }^{\circ} \mathrm{C}$ in DEG did not significantly change the product's purity or yield.

Obviously, $\mathrm{CuCl}_{2}$ and $\mathrm{CuSO}_{4}$ are not well suited for the precipitation of metallic copper in boiling EG without further modifying the process. Syntheses starting from these materials described in the literature always required the addition of 3-4 eq. of hydroxide. ${ }^{14,18}$

The light blue solution of copper(II) nitrate in EG does not change up to $160{ }^{\circ} \mathrm{C}$. At $180{ }^{\circ} \mathrm{C}$ the formation of nitrous gases is observed, and after $20 \mathrm{~min}$ a brown suspension occurs. The precipitate isolated by centrifugation mainly consists of $\mathrm{Cu}_{2} \mathrm{O}$ (Fig. 1). The dispersion is rather stable and difficult to separate completely by centrifugation. This agrees with the previously described colloidal stability of oxide nanoparticles in polyols up to $20 \mathrm{wt} \% .^{22} \mathrm{~A}$ small reflection in the powder patterns can be assigned to copper(II) oxalate $\mathrm{Cu}\left(\mathrm{C}_{2} \mathrm{O}_{4}\right) \cdot x \mathrm{H}_{2} \mathrm{O}(x=0-1$, PDF number 21-297). IR spectra confirm the presence of carboxyl groups (Fig. $\mathrm{S} 2 \dagger$ ). The formation of the byproduct is enabled by the oxidation of EG to oxalate under simultaneous reduction of nitrate to nitrous gases according to (5).

$$
\mathrm{NO}_{3}{ }^{-}+4 \mathrm{H}^{+}+3 \mathrm{e}^{-} \rightarrow \mathrm{NO}+2 \mathrm{H}_{2} \mathrm{O} \quad E^{\circ}=+0.957 \mathrm{~V}
$$

Under reflux conditions at $210{ }^{\circ} \mathrm{C}$ a dark red suspension of pure elemental copper is formed after some minutes. No $\mathrm{Cu}_{2} \mathrm{O}$ 


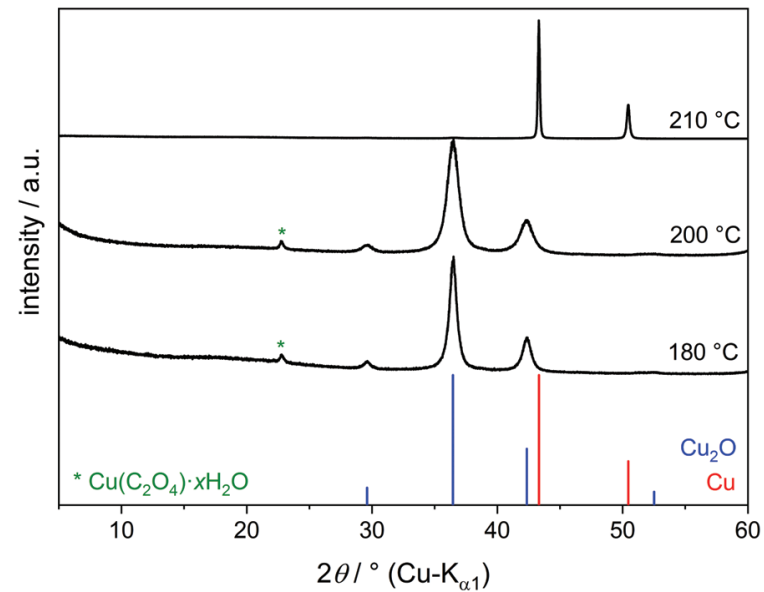

Fig. 1 PXRD patterns of reaction products of $\mathrm{Cu}\left(\mathrm{NO}_{3}\right)_{2} \cdot 2.5 \mathrm{H}_{2} \mathrm{O}$ in EG at various temperatures.

was detected by PXRD (Fig. 1). However, the surface of copper particles is easily oxidised by air if no precautions are taken to prevent this. ${ }^{12}$ Such a surface layer of copper oxide is likely to be present for all the products in this study since the reactions were carried out under air and without surfactants. The amorphous surface layer is probably only a few nanometres thick. Rietveld refinements of some of the finally obtained copper powders, mixed with a known amount of silicon standard material, showed no notable amorphous content in the products.

Copper(II) hydroxide does not dissolve in EG even upon prolonged heating but transforms into an EG-containing solid. The PXRD patterns of the products obtained at $120-180{ }^{\circ} \mathrm{C}$ show primarily one intense broad reflection at $2 \theta=10.8^{\circ}$ (Fig. 2). A Cu-EG compound with a similar powder pattern was obtained from copper acetate in EG and described as a precursor for the production of nanostructured CuO. However, this compound was not further characterised. ${ }^{15}$

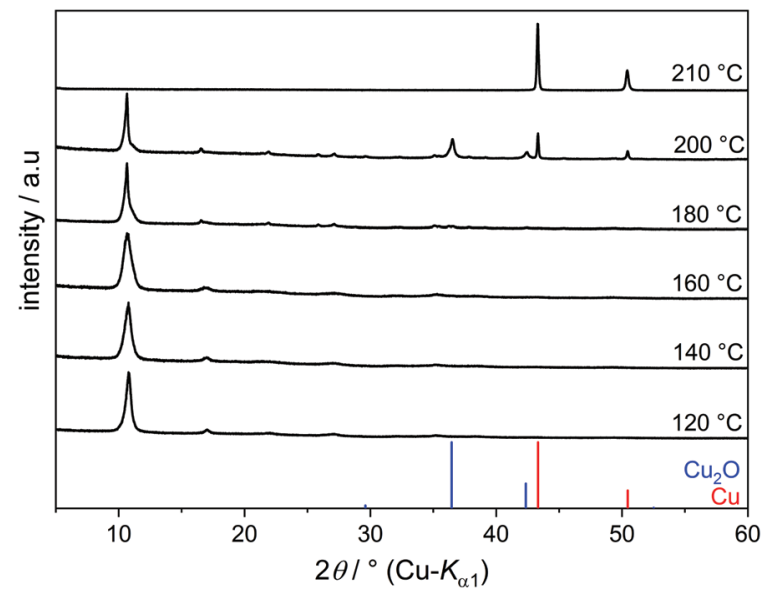

Fig. 2 PXRD patterns of reaction products of $\mathrm{Cu}(\mathrm{OH})_{2}$ in $\mathrm{EG}$ at various temperatures.

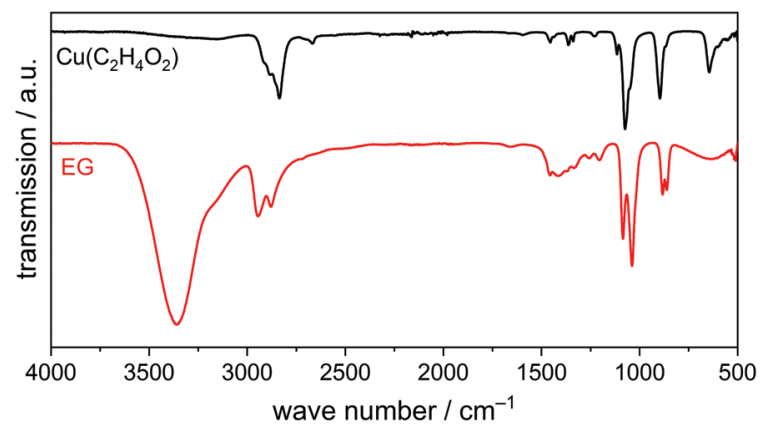

Fig. 3 IR spectra of $\mathrm{Cu}\left(\mathrm{C}_{2} \mathrm{H}_{4} \mathrm{O}_{2}\right)$ and liquid $\mathrm{EG}$.

The IR spectrum of this precipitate (Fig. 3) shows some absorption bands similar to those of liquid EG: bands due to $\mathrm{CH}$ stretching (2950-2850 $\left.\mathrm{cm}^{-1}\right), \quad \mathrm{C}-\mathrm{O}$ stretching (1100-1000 $\mathrm{cm}^{-1}$ ), C-C stretching and $\mathrm{CH}_{2}$ deformation (ca. $900 \mathrm{~cm}^{-1}$ ) are clearly visible in the spectrum. The absence of the broad $\mathrm{OH}$ stretching band at $3600-3000 \mathrm{~cm}^{-1}$ and $\mathrm{C}-\mathrm{OH}$ deformation bands at $1450-1300 \mathrm{~cm}^{-1}$, on the other hand, indicates fully deprotonated EG molecules. The $\mathrm{CH}$ stretching vibrations are split as compared to liquid EG most probably because of a chelating coordination of the EG molecules. In combination with results from elemental analysis (measured: C 18.1 wt\%, H 2.9 wt\%, calculated: C 19.4 wt\%, H 3.3 wt\%) and the $\mathrm{Cu}$ content determined from the $\mathrm{CuO}$ residual after heating in air (determined: $\mathrm{Cu} 52.3$ wt\%, calculated: $\mathrm{Cu}$ $51.4 \mathrm{wt} \%$ ), we propose that the solid alkoxide yielded in this study is (ethylene glycolato)-copper(II), $\mathrm{Cu}\left(\mathrm{C}_{2} \mathrm{H}_{4} \mathrm{O}_{2}\right)$.

Hence, copper hydroxide reacts with $\mathrm{EG}$ molecules to form the alkoxide upon the release of water:

$$
\mathrm{Cu}(\mathrm{OH})_{2}+\mathrm{C}_{2} \mathrm{H}_{6} \mathrm{O}_{2} \rightarrow \mathrm{Cu}\left(\mathrm{C}_{2} \mathrm{H}_{4} \mathrm{O}_{2}\right)+2 \mathrm{H}_{2} \mathrm{O}
$$

The powder pattern of the produced alkoxide is very similar to those commonly found for layered hydroxide salts. ${ }^{23}$ In the crystal structure of $\mathrm{Cu}(\mathrm{OH})_{2}$, strongly Jahn-Teller distorted $\mathrm{CuO}_{6}$ octahedra are edge-linked to corrugated layers. ${ }^{24}$ These layers are stacked along the $b$ axis with a distance of 530 pm (Fig. 4a). Corrugated layers of edge-linked $\mathrm{CuO}_{6}$ octahedra are also found in copper(II) layered hydroxide salts, e.g. $\mathrm{Cu}_{2}(\mathrm{OH})_{3}(\mathrm{OAc})^{25}$ Assuming a similar structure for $\mathrm{Cu}\left(\mathrm{C}_{2} \mathrm{H}_{4} \mathrm{O}_{2}\right)$, the $d$-spacing of the most intense reflection corresponds to an interlayer spacing of $820 \mathrm{pm}$, probably due

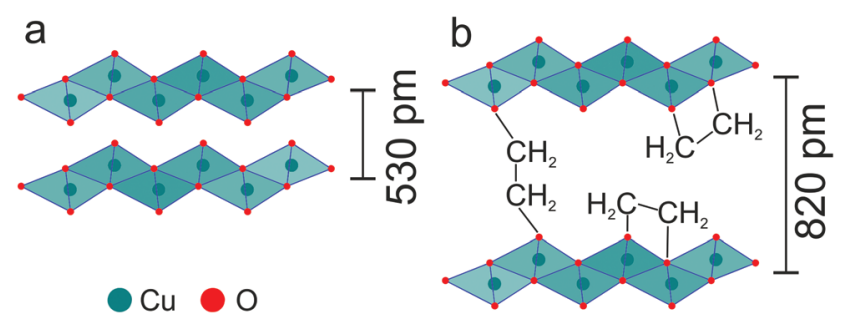

Fig. 4 Crystal structure of $\mathrm{Cu}(\mathrm{OH})_{2}(\mathrm{a})$ and a proposed structure model of $\mathrm{Cu}\left(\mathrm{C}_{2} \mathrm{H}_{4} \mathrm{O}_{2}\right)(\mathrm{b})$. 
to deprotonated EG ligands occupying the interlayer space (Fig. 4b). The EG ligands might show an intralayer-chelating or interlayer-bridging coordination mode or a mixture of both.

Similar to $\mathrm{Cu}\left(\mathrm{C}_{2} \mathrm{H}_{4} \mathrm{O}_{2}\right)$, the solid alkoxides $\mathrm{Co}\left(\mathrm{C}_{2} \mathrm{H}_{4} \mathrm{O}_{2}\right)^{26}$ and $\mathrm{Ni}\left(\mathrm{C}_{2} \mathrm{H}_{4} \mathrm{O}_{2}\right)^{27}$ have been obtained by heating $\mathrm{Co}(\mathrm{OAc})_{2}$ and $\mathrm{Ni}(\mathrm{OH})_{2}$ in EG, respectively. Both compounds were described as layered brucite-like structures with turbostratic disorder. The interlayer spacing of $830 \mathrm{pm}$ is close to the value for $\mathrm{Cu}\left(\mathrm{C}_{2} \mathrm{H}_{4} \mathrm{O}_{2}\right)$ determined in this study. The reported PXRD patterns and IR spectra show some similarities to those of $\mathrm{Cu}\left(\mathrm{C}_{2} \mathrm{H}_{4} \mathrm{O}_{2}\right)$.

According to DTA-TG measurements in air (Fig. S3†), $\mathrm{Cu}\left(\mathrm{C}_{2} \mathrm{H}_{4} \mathrm{O}_{2}\right)$ is mainly reduced to $\mathrm{Cu}_{2} \mathrm{O}$ in the first thermal decomposition step at about $200{ }^{\circ} \mathrm{C}$. The oxidation of $\mathrm{Cu}_{2} \mathrm{O}$ to the final product $\mathrm{CuO}$ leads to a mass increase between $220^{\circ} \mathrm{C}$ and $400{ }^{\circ} \mathrm{C}$. $\mathrm{Cu}\left(\mathrm{C}_{2} \mathrm{H}_{4} \mathrm{O}_{2}\right)$ is paramagnetic. The temperature dependence of the inverse susceptibility $\chi^{-1}(T)$ (Fig. $\mathrm{S} 4 \dagger$ ) can be modelled above $100 \mathrm{~K}$ by a Curie-Weiss law with the Curie constant $C_{\mathrm{mol}}=0.350 \mathrm{~cm}^{3} \mathrm{~K} \mathrm{~mol}^{-1}$ and the Curie-Weiss temperature $\Theta=-61 \mathrm{~K}$, indicating antiferromagnetic coupling. The effective magnetic moment per $\mathrm{Cu}$ atom of $\mu_{\mathrm{eff}}=1.67 \mu_{\mathrm{B}}$ derived from $C_{\mathrm{mol}}$ is in good agreement with the spin-only value of 1.73 expected for $\mathrm{Cu}^{2+}$ ions in a Jahn-Teller distorted octahedral environment. The $\chi^{-1}(T)$ curve shows a steady decrease upon lowering the temperature to $2 \mathrm{~K}$ which might be an indication of magnetic frustration.

When reacting $\mathrm{Cu}(\mathrm{OH})_{2}$ in $\mathrm{EG}$ at $120-180^{\circ} \mathrm{C}$, the main fraction (more than $80 \%$ ) of $\mathrm{Cu}^{2+}$ precipitates as $\mathrm{Cu}\left(\mathrm{C}_{2} \mathrm{H}_{4} \mathrm{O}_{2}\right)$ and only a minor fraction of $\mathrm{Cu}^{2+}$ species remains dissolved. At $200{ }^{\circ} \mathrm{C}, \mathrm{Cu}^{2+}$ is reduced to $\mathrm{Cu}_{2} \mathrm{O}$. The Bragg reflections of $\mathrm{Cu}_{2} \mathrm{O}$ are broad, indicating small domain sizes. Elemental copper is obtained under reflux conditions at $210{ }^{\circ} \mathrm{C}$.

SEM images (Fig. 5) show drastic changes in the size and morphology of the solids collected from the reaction mixtures. The starting material $\mathrm{Cu}(\mathrm{OH})_{2}$ consists of prolate nanoparticles. The appearance of $\mathrm{Cu}\left(\mathrm{C}_{2} \mathrm{H}_{4} \mathrm{O}_{2}\right)$ changes between $120{ }^{\circ} \mathrm{C}$ and $200{ }^{\circ} \mathrm{C}$ from highly agglomerated almost isotropic

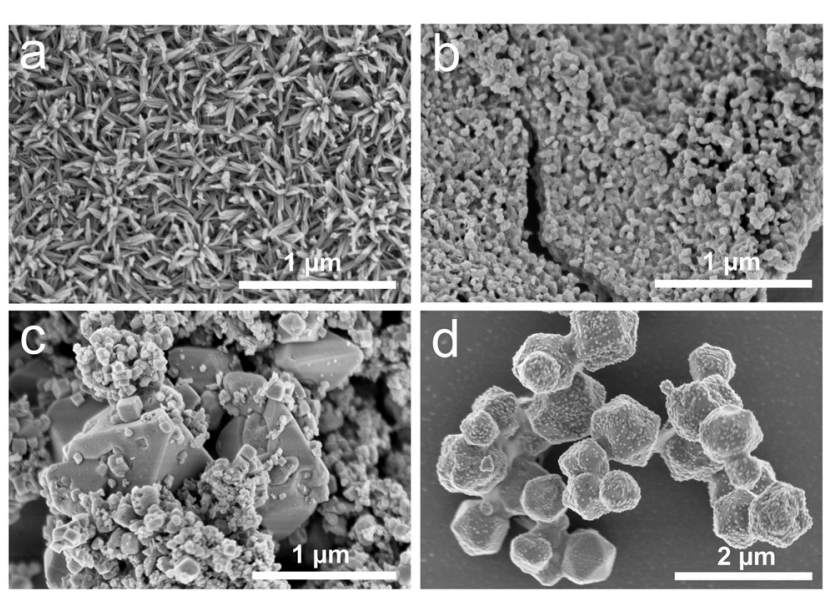

Fig. 5 SEM pictures of starting material $\mathrm{Cu}(\mathrm{OH})_{2}(\mathrm{a}), \mathrm{Cu}\left(\mathrm{C}_{2} \mathrm{H}_{4} \mathrm{O}_{2}\right)$ (b), $\mathrm{Cu}\left(\mathrm{C}_{2} \mathrm{H}_{4} \mathrm{O}_{2}\right)$ and $\mathrm{Cu}_{2} \mathrm{O}(\mathrm{c})$, and copper particles (d). nanoparticles (Fig. 5b) to facetted crystals up to $3 \mu \mathrm{m}$ length (Fig. 5c). The cubic $\mathrm{Cu}_{2} \mathrm{O}$ particles with edge lengths up to $100 \mathrm{~nm}$ are well-stabilised in the reaction medium and rather difficult to precipitate completely by centrifugation. Due to the low $\mathrm{Cu}^{2+}$ concentration in solution prior to nucleation, the number of formed nuclei is limited and therefore copper submicron-sized particles (Fig. 5d) rather than nanoparticles are formed. These particles are poorly stabilised in EG and tend to agglomerate rapidly as the reaction time is increased.

Combining the PXRD and IR results the reaction scheme (7) of $\mathrm{Cu}(\mathrm{OH})_{2}$ with EG can be deducted.

$$
\mathrm{Cu}(\mathrm{OH})_{2} \rightarrow \mathrm{Cu}\left(\mathrm{C}_{2} \mathrm{H}_{4} \mathrm{O}_{2}\right) \rightarrow \mathrm{Cu}_{2} \mathrm{O} \rightarrow \mathrm{Cu}
$$

By adding 2 eq. of $\mathrm{NaOH}$ to a suspension of $\mathrm{Cu}(\mathrm{OH})_{2}$ in $\mathrm{EG}$, a clear, dark blue solution is formed. $\mathrm{Cu}^{2+}$ might exist in this solution in the form of square-planar $\left[\mathrm{Cu}(\mathbf{O H})_{4}\right]^{2-}$ or $\left[\mathbf{C u}\left(\mathbf{C}_{2} \mathbf{H}_{4} \mathbf{O}_{2}\right)_{2}\right]^{2-}$ complexes. The $\left[\mathrm{Cu}(\mathrm{OH})_{4}\right]^{2-}$ species exists in alkaline aqueous solutions. ${ }^{28}\left[\mathrm{Cu}\left(\mathrm{C}_{2} \mathrm{H}_{4} \mathrm{O}_{2}\right)_{2}\right]^{2-}$ ions, which might be more stable in the EG solution because of the chelate effect, are known from crystals formed in alkaline mixtures of $\mathrm{Cu}^{2+}$ and group 1 or 2 metal ions in EG. ${ }^{29-32}$

A copper alkoxide intermediate precipitates from the dark blue solution by heating to $120^{\circ} \mathrm{C}$. IR spectra and TG curves of this precipitate are very similar to those of $\mathrm{Cu}\left(\mathrm{C}_{2} \mathrm{H}_{4} \mathrm{O}_{2}\right)$ obtained without $\mathrm{NaOH}$, but the PXRD pattern (Fig. 6) is slightly different. Instead of one dominating reflection at $2 \theta=$ $10.8^{\circ}$ one pronounced reflection at $10.4^{\circ}$ and a less intense one at $11.2^{\circ}$ are found, corresponding to interlayer distances of $850 \mathrm{pm}$ and $790 \mathrm{pm}$, respectively. This suggests a structural variability of $\mathrm{Cu}\left(\mathrm{C}_{2} \mathrm{H}_{4} \mathrm{O}_{2}\right)$, which might arise from different coordination modes of the EG ligands influencing the interlayer spacing. The yield of $\mathrm{Cu}\left(\mathrm{C}_{2} \mathrm{H}_{4} \mathrm{O}_{2}\right)(\mathrm{ca}$. 40\%) is much lower than with pure $\mathrm{Cu}(\mathrm{OH})_{2}$ as the starting material due to a higher solubility of copper(II) species in the alkaline solution.

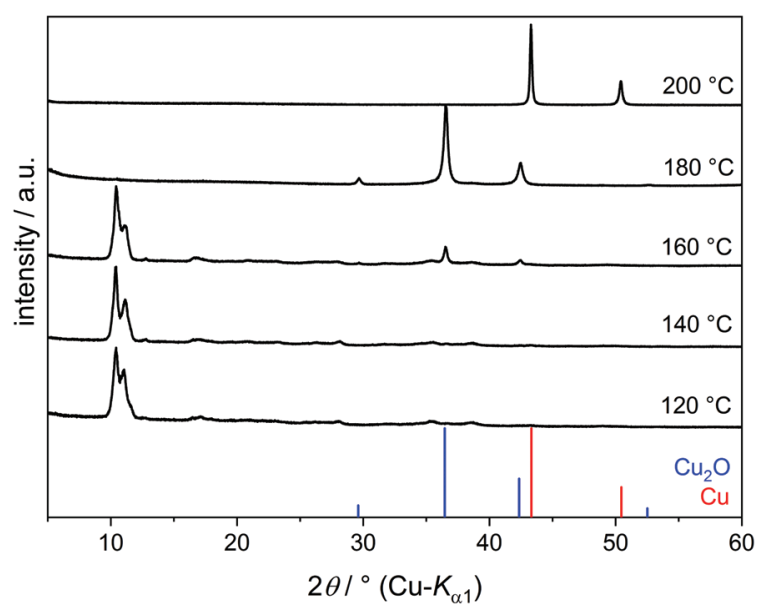

Fig. 6 PXRD patterns of reaction products of $\mathrm{Cu}(\mathrm{OH})_{2}$ and 2 eq. of $\mathrm{NaOH}$ in $\mathrm{EG}$ at various temperatures. 
The reduction of $\left[\mathrm{Cu}\left(\mathrm{C}_{2} \mathrm{H}_{4} \mathrm{O}_{2}\right)_{2}\right]^{2-}$ to elemental copper proceeds according to the reaction scheme (7) shown above, but at a significantly lower temperature compared to pure $\mathrm{Cu}(\mathrm{OH})_{2}$. According to PXRD results, $\mathrm{Cu}_{2} \mathrm{O}$ begins to form at $160{ }^{\circ} \mathrm{C}$ and quantitatively transforms to $\mathrm{Cu}$ at $200{ }^{\circ} \mathrm{C}$. This could be due to the solubility of the precursor as well as the increased $\mathrm{pH}$ value. Hydroxide ions are assumed to initiate the reaction by deprotonation of the $\alpha$-carbon atom of the $\left(\mathrm{C}_{2} \mathrm{H}_{4} \mathrm{O}_{2}\right)^{2-}$ ligand, thus leaving two electrons for the reduction of the metal cation. ${ }^{18}$

The majority of the finally obtained, severely agglomerated $\mathrm{Cu}$ particles (Fig. 7) have a significantly smaller size compared to those obtained from pure $\mathrm{Cu}(\mathrm{OH})_{2}$ due to a higher concentration of $\mathrm{Cu}^{2+}$ in the reaction solution prior to nucleation.

Copper(II) acetate completely dissolves in EG at $c a .80{ }^{\circ} \mathrm{C}$ yielding a bright turquoise solution. Further heating to $120^{\circ} \mathrm{C}$ leads to the precipitation of a dark green crystalline compound (Fig. 8). The IR spectrum of this compound (Fig. 9) shows $\mathrm{CH}$ stretching $\quad\left(2950-2850 \quad \mathrm{~cm}^{-1}\right), \quad \mathrm{C}-\mathrm{O} \quad$ stretching (1100-1000 $\mathrm{cm}^{-1}$ ), C-C stretching and $\mathrm{CH}_{2}$ deformation (ca. $900 \mathrm{~cm}^{-1}$ ), but no OH stretching band, indicating fully deprotonated EG groups. Bands in the range $1600-1300 \mathrm{~cm}^{-1}$ are due to $\mathrm{COO}$ stretching and $\mathrm{CH}_{3}$ deformation because of the presence of acetate ions.

The structure determination of the obtained product by single-crystal $\mathrm{X}$-ray diffraction revealed the coordination polymer $\mathrm{Cu}_{3}(\mathrm{OAc})_{2}\left(\mathrm{C}_{2} \mathrm{H}_{4} \mathrm{O}_{2}\right)_{2}$. It crystallises in the triclinic space group $P \overline{1}$ and shows a $2 \mathrm{D}$ network structure generated by bridging bidentate acetate and deprotonated EG ligands (Fig. 10). The three crystallographically independent $\mathrm{Cu}$ atoms have approximately square-pyramidal coordination environments of $\mathrm{O}$ atoms. Four $\mathrm{O}$ atoms are located in distances of 192-200 pm forming a distorted square-planar array. The apical $\mathrm{O}$ atoms are more remote with distances between $224.6 \mathrm{pm}$ and $251.4 \mathrm{pm}$. Valence-bond $\mathrm{sums}^{33}$ of 2.11 (Cu1) and $2.04(\mathrm{Cu} 2, \mathrm{Cu} 3)$ unambiguously indicate copper(II). The $\mathrm{CuO}_{5}$ pyramids are linked via their edges and vertices forming

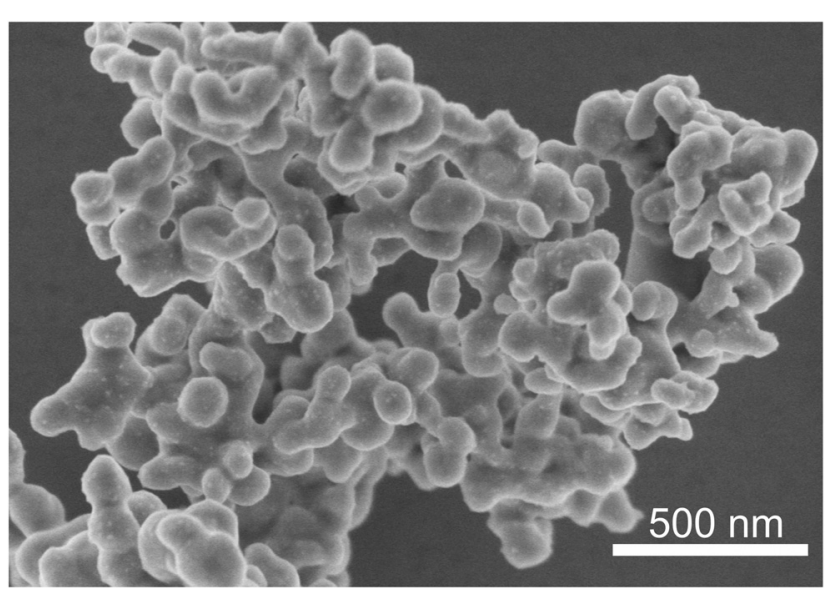

Fig. 7 SEM picture of copper particles obtained from $\mathrm{Cu}(\mathrm{OH})_{2}$ and 2 eq. of $\mathrm{NaOH}$ in $\mathrm{EG}$ at $200^{\circ} \mathrm{C}$.

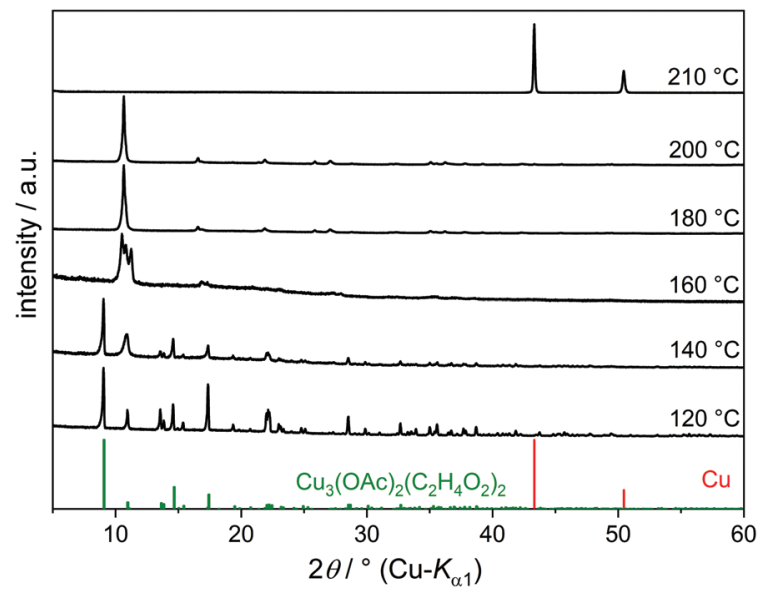

Fig. 8 PXRD patterns of reaction products of $\mathrm{Cu}(\mathrm{OAc})_{2} \cdot \mathrm{H}_{2} \mathrm{O}$ in EG obtained at various temperatures. The reference pattern for $\mathrm{Cu}_{3}(\mathrm{OAc})_{2}\left(\mathrm{C}_{2} \mathrm{H}_{4} \mathrm{O}_{2}\right)_{2}$ was simulated from the single-crystal structure data.

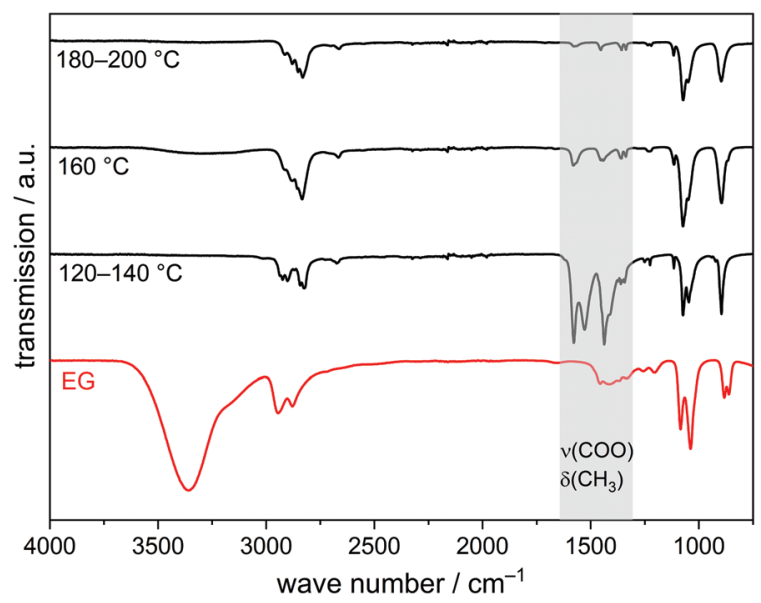

Fig. 9 IR spectra of reaction products from $\mathrm{Cu}(\mathrm{OAc})_{2} \cdot \mathrm{H}_{2} \mathrm{O}$ in EG obtained at different temperatures.

bands along [100] that consist of alternating $\mathrm{Cu}_{6} \mathrm{O}_{6}$ and $\mathrm{Cu}_{4} \mathrm{O}_{4}$ rings. The longest $\mathrm{Cu}-\mathrm{O}$ distance of $251.4 \mathrm{pm}$ (at $\mathrm{Cu} 2$ ) links the chains to a strongly corrugated layer parallel (001). The layers are stacked along the $c$ axis and not linked via hydrogen bonds.

The mixed coordination of metal cations to solely doubledeprotonated EG and acetate ligands, which occurs in $\mathrm{Cu}_{3}(\mathrm{OAc})_{2}\left(\mathrm{C}_{2} \mathrm{H}_{4} \mathrm{O}_{2}\right)_{2}$, was also reported for the compound $\mathrm{Sb}(\mathrm{OAc})\left(\mathrm{C}_{2} \mathrm{H}_{4} \mathrm{O}_{2}\right) \cdot{ }^{34}$ Mono-deprotonated EG molecules were found in $\mathrm{Zn}_{2}(\mathrm{OAc})_{3}\left(\mathrm{C}_{2} \mathrm{H}_{5} \mathrm{O}_{2}\right){ }^{35}$ The occurrence of deprotonated EG is rather unusual, especially regarding the fact that no base was added to the reaction mixture. Acetic acid $\left(\mathrm{p} K_{\mathrm{a}}=4.75\right)$ is a much stronger acid than EG $\left(\mathrm{p} K_{\mathrm{a}}=15.1\right),{ }^{19}$ and therefore the deprotonation of EG by acetate anions is an unlikely process. However, the stability of the product compound or the evaporation of acetic acid from the reaction solution may drive the reaction. The yield of the precipitated alkoxide is $c a$. $50 \%$. 


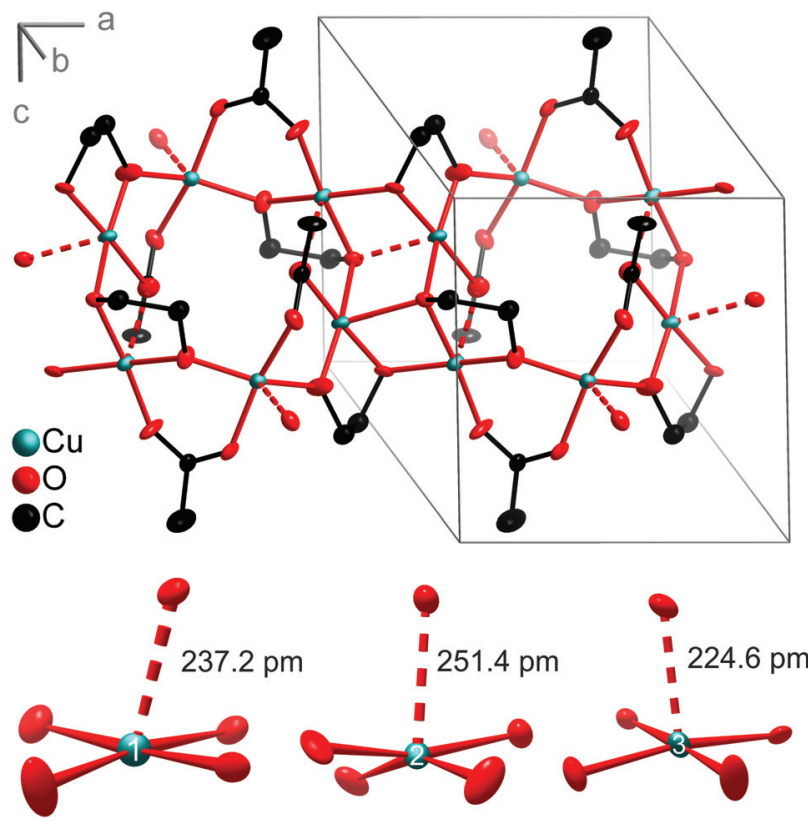

Fig. 10 Crystal structure of $\mathrm{Cu}_{3}(\mathrm{OAc})_{2}\left(\mathrm{C}_{2} \mathrm{H}_{4} \mathrm{O}_{2}\right)_{2}$ and coordination environment of the three independent $\mathrm{Cu}$ atoms. The longest $\mathrm{Cu}-\mathrm{O}$ distances are represented by dashed lines. Hydrogen atoms are omitted for clarity. Ellipsoids represent a probability density of $90 \%$.

DTA-TG measurements of dry $\mathrm{Cu}_{3}(\mathrm{OAc})_{2}\left(\mathrm{C}_{2} \mathrm{H}_{4} \mathrm{O}_{2}\right)_{2}$ in air (Fig. S5 $\dagger$ ) showed that the compound is stable up to $200{ }^{\circ} \mathrm{C}$ and decomposes in an exothermic reaction to $\mathrm{Cu}_{2} \mathrm{O}$ and then to the final product $\mathrm{CuO} . \mathrm{Cu}_{3}(\mathrm{OAc})_{2}\left(\mathrm{C}_{2} \mathrm{H}_{4} \mathrm{O}_{2}\right)_{2}$ shows paramagnetic behaviour. The $\chi^{-1}$ plot (Fig. S6 $\dagger$ ) can be modelled above $200 \mathrm{~K}$ by a Curie-Weiss fit. The obtained Curie constant $C_{\mathrm{mol}}=$ $0.412 \mathrm{~cm}^{3} \mathrm{~K} \mathrm{~mol}^{-1}$ corresponds to an effective magnetic moment $\mu_{\text {eff }}=1.81 \mu_{\mathrm{B}}$, which is slightly higher than the spinonly value of $1.73 \mu_{\mathrm{B}}$ expected for $\mathrm{Cu}^{2+}$ ions.

The acetate-alkoxide coordination polymer is not stable at reaction temperatures of $160^{\circ} \mathrm{C}$ and higher. Products isolated after $30 \mathrm{~min}$ at $180{ }^{\circ} \mathrm{C}$ and $200^{\circ} \mathrm{C}$ show PXRD patterns (Fig. 8) and IR spectra (Fig. 9) characteristic for the already described compound $\mathrm{Cu}\left(\mathrm{C}_{2} \mathrm{H}_{4} \mathrm{O}_{2}\right)$. The solid alkoxide is formed in high yields and only a small amount of $\mathrm{Cu}^{2+}$ remains in solution. Elemental copper is obtained under reflux conditions at $210{ }^{\circ} \mathrm{C} . \mathrm{Cu}_{2} \mathrm{O}$ could not be detected after $30 \mathrm{~min}$ because of its small stability range in this particular reaction system, which is accompanied by the high stability of $\mathrm{Cu}\left(\mathrm{C}_{2} \mathrm{H}_{4} \mathrm{O}_{2}\right)$.

By combining the PXRD and IR results, reaction scheme (8) can be deducted for the reduction of copper acetate in EG.

$$
\begin{aligned}
\mathrm{Cu}(\mathrm{OAc})_{2} \cdot \mathrm{H}_{2} \mathrm{O} & \rightarrow \mathrm{Cu}_{3}(\mathrm{OAc})_{2}\left(\mathrm{C}_{2} \mathrm{H}_{4} \mathrm{O}_{2}\right)_{2} \\
& \rightarrow \mathrm{Cu}\left(\mathrm{C}_{2} \mathrm{H}_{4} \mathrm{O}_{2}\right) \rightarrow \mathrm{Cu}
\end{aligned}
$$

\section{Reduction of copper(II) in higher glycol ethers}

Besides EG, the reduction of copper(II) hydroxide and acetate was also monitored in the longer-chain diols DEG, TrEG, and TEG. The resulting solid phases starting from copper hydroxide and acetate are summarised in Tables 1 and 2, respectively.
Table 1 Stability ranges (in ${ }^{\circ} \mathrm{C}$ ) of obtained solid compounds starting from $\mathrm{Cu}(\mathrm{OH})_{2}$ after a reaction time of $30 \mathrm{~min}$

\begin{tabular}{lllll}
\hline Polyol & $\mathrm{Cu}(\mathrm{OH})_{2}$ & Alkoxide & $\mathrm{Cu}_{2} \mathrm{O}$ & $\mathrm{Cu}$ \\
\hline EG & & $120-200$ & 200 & $\geq 210$ \\
DEG & & $120-200$ & $180-200$ & $\geq 220$ \\
TrEG & 120 & $120-180$ & $180-200$ & $\geq 220$ \\
TEG & $120-160$ & & $140-220$ & $\geq 200$
\end{tabular}

Table 2 Stability ranges (in ${ }^{\circ} \mathrm{C}$ ) of obtained solid compounds starting from $\mathrm{Cu}(\mathrm{OAc})_{2} \cdot \mathrm{H}_{2} \mathrm{O}$ after a reaction time of $30 \mathrm{~min}$

\begin{tabular}{lllll}
\hline Polyol & Acetate-alkoxide & Alkoxide & $\mathrm{Cu}_{2} \mathrm{O}$ & $\mathrm{Cu}$ \\
\hline EG & $120-140$ & $160-200$ & & $\geq 210$ \\
DEG & 120 & $140-200$ & $200-220$ & $\geq 220$ \\
TrEG & & & $140-240$ & $\geq 240$ \\
TEG & & & $120-240$ & $\geq 240$
\end{tabular}

On reacting $\mathrm{Cu}(\mathrm{OH})_{2}$ with DEG, an alkoxide compound is obtained between $120^{\circ} \mathrm{C}$ and $200{ }^{\circ} \mathrm{C}$. PXRD patterns (Fig. 11) show an intense reflection at $2 \theta=11.0^{\circ}$ and weaker reflections at $16.2^{\circ}(d=550 \mathrm{pm})$ and $32.7^{\circ}(d=270 \mathrm{pm})$. IR spectra indicate the absence of acetate in this compound as they only show bands associated with the DEG molecules. No $\mathrm{OH}$ stretching band can be observed, although in some samples there is a broad signal around $3000 \mathrm{~cm}^{-1}$ arising from adsorbed water or DEG molecules. The formula deducted for this alkoxide compound is $\mathrm{Cu}\left(\mathrm{C}_{4} \mathrm{H}_{8} \mathrm{O}_{3}\right)$ which is in agreement with results from elemental analysis (measured: C $28.7 \mathrm{wt} \%$, $\mathrm{H} 4.8 \mathrm{wt} \%$, calculated: C $28.7 \mathrm{wt} \%, \mathrm{H} 4.8 \mathrm{wt} \%$ ) and the $\mathrm{Cu}$ content calculated from the $\mathrm{CuO}$ residual after heating in air (determined: $36.8 \mathrm{wt} \%$, calculated: $37.9 \mathrm{wt} \%$ ). The compound described here had already been synthesised and two structural models, containing either mono-deprotonated or a mixture of double-deprotonated and neutral DEG molecules, had been proposed. ${ }^{16}$ However, no or only very few $\mathrm{OH}$

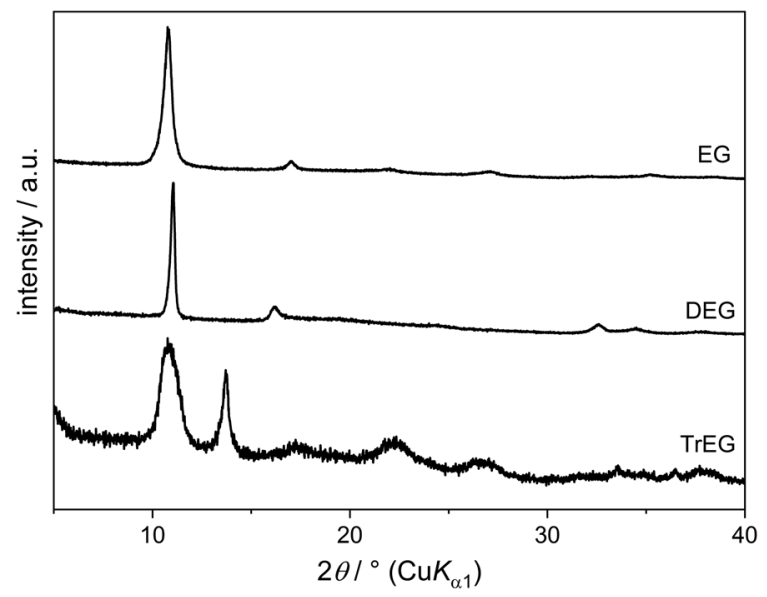

Fig. 11 PXRD patterns of alkoxides synthesised from the reaction of $\mathrm{Cu}(\mathrm{OH})_{2}$ with EG, DEG, and TrEG. 
groups might be present in the structure according to our results.

The starting compound $\mathrm{Cu}(\mathrm{OH})_{2}$ can still be found in the solid products obtained with TrEG and TEG up to $140{ }^{\circ} \mathrm{C}$ and $160{ }^{\circ} \mathrm{C}$, respectively. Similar to EG and DEG, an alkoxide compound is formed with TrEG. The PXRD pattern (Fig. 11) shows intense broad reflections at $2 \theta=10.8^{\circ}(d=820 \mathrm{pm})$ and $13.7^{\circ}$ $(d=645 \mathrm{pm})$.

In contrast to the previously discussed polyols TEG does not form an alkoxide compound with $\mathrm{Cu}^{2+}$. Only $\mathrm{Cu}(\mathrm{OH})_{2}$, $\mathrm{Cu}_{2} \mathrm{O}$ and copper can be detected in the obtained solid by PXRD. IR spectra show weak $\mathrm{CH}$ and $\mathrm{C}-\mathrm{O}$ stretching bands, possibly due to TEG molecules adsorbed to the particle surface.

With copper acetate as precursor material (Table 2), only with EG and DEG alkoxides are formed. Similar to the reaction sequence in EG, an acetate-alkoxide compound is formed when copper acetate is heated in DEG to $120{ }^{\circ} \mathrm{C}$. Both DEG and carboxylate vibration bands are visible in the IR spectrum of the precipitate. The powder diffractogram shows one intense and sharp reflection at $2 \theta=9.4^{\circ}(d=940 \mathrm{pm})$. At $140{ }^{\circ} \mathrm{C}$ desert-rose shaped particles of $\mathrm{Cu}\left(\mathrm{C}_{4} \mathrm{H}_{8} \mathrm{O}_{3}\right)$ are obtained (Fig. S11†). $\mathrm{Cu}\left(\mathrm{C}_{4} \mathrm{H}_{8} \mathrm{O}_{3}\right)$ transforms to $\mathrm{Cu}_{2} \mathrm{O}$ and finally to copper. No alkoxide compounds could be detected for TrEG and TEG. However, the reduction to $\mathrm{Cu}^{+}$starts at a much lower temperature and the stability range of $\mathrm{Cu}_{2} \mathrm{O}$ is significantly enhanced. There is a small amount of a byproduct at $180{ }^{\circ} \mathrm{C}$ for TrEG and at $160^{\circ} \mathrm{C}$ for TEG (Fig. S8 $\dagger$ ). IR spectra of the samples show intense carbonyl bands at $1650 \mathrm{~cm}^{-1}$ (Fig. S14 $\dagger$ ). Elemental copper is produced at higher temperatures when compared to copper acetate as the starting material. This is due to the stronger alkalinity of $\mathrm{Cu}(\mathrm{OH})_{2}$ which leads to deprotonation of EG molecules.

\section{Coordination affinity of anions to copper(II) in ethylene glycol}

Experiments including more than one anion in the solution showed some trends from which a general sequence of affinity towards $\mathrm{Cu}^{2+}$ could be deducted. Addition of $\mathrm{NaOH}$ to mixtures of $\mathrm{CuCl}_{2}, \mathrm{CuSO}_{4}, \mathrm{Cu}\left(\mathrm{NO}_{3}\right)_{2}$, or $\mathrm{Cu}(\mathrm{OAc})_{2}$ in EG first yields a light blue precipitate ( 2 eq. of $\mathrm{NaOH}$ ), which subsequently dissolves resulting in a dark blue solution (4 eq. of $\mathrm{NaOH}$ ). The reaction behaviour of these solutions is very similar to that of $\mathrm{Cu}(\mathrm{OH})_{2}$ or $\left[\mathrm{Cu}(\mathrm{OH})_{4}\right]^{2-} /\left[\mathrm{Cu}\left(\mathrm{C}_{2} \mathrm{H}_{4} \mathrm{O}_{2}\right)_{2}\right]^{2-}$. With 4 eq. of $\mathrm{NaOH}$, the complete reduction of the starting material to elemental copper can be achieved at $180^{\circ} \mathrm{C}$. Seemingly, anions other than hydroxide do not affect the reduction. However, with sulfate anions $\mathrm{Na}_{2} \mathrm{SO}_{4}$ was formed as byproduct during the reaction (Fig. $\mathrm{S} 7 \dagger$ ). $\mathrm{Na}_{2} \mathrm{SO}_{4}$ is only sparingly soluble in EG and has to be removed from the solid product by multiple washing cycles.

Addition of 2 eq. of NaOAc to solutions of $\mathrm{CuCl}_{2}, \mathrm{CuSO}_{4}$, and $\mathrm{Cu}\left(\mathrm{NO}_{3}\right)_{2}$ produces bright turquoise solutions which show the same reaction behaviour as those of pure $\mathrm{Cu}(\mathrm{OAc})_{2}$. Remarkably, $\mathrm{CuCl}_{2}$ can be reduced to elemental copper at $210^{\circ} \mathrm{C}$ (Fig. S7 $\dagger$ ). Because of its chelating ability, acetate seems to be a stronger ligand for $\mathrm{Cu}^{2+}$ than chloride.
The addition of 2 eq. of $\mathrm{NaCl}$ prevents the reduction of $\mathrm{Cu}\left(\mathrm{NO}_{3}\right)_{2}$ or $\mathrm{CuSO}_{4}$ to elemental copper. Clear solutions without any solid products were obtained after $30 \mathrm{~min}$ at $210{ }^{\circ} \mathrm{C}$. Chloride acts as a Lewis base and directly binds to $\mathrm{Cu}^{2+}$, probably forming the solution species $\left[\mathrm{CuCl}_{2}(\mathrm{EG})_{2}\right]$, which leads to the same reaction behaviour as for $\mathrm{CuCl}_{2}$.

Based on these results, we propose a sequence of decreasing affinity towards $\mathrm{Cu}^{2+}$ ions in EG solutions: hydroxide > acetate $>$ chloride $>$ nitrate/sulfate.

\section{Conclusions}

Systematic experiments were carried out to study the aniondependent course of the reduction of copper(II) salts in polyols. Elemental copper can only be obtained in high yields starting from $\mathrm{Cu}\left(\mathrm{NO}_{3}\right)_{2}, \mathrm{Cu}(\mathrm{OAc})_{2}$, or $\mathrm{Cu}(\mathrm{OH})_{2}$; but not with $\mathrm{CuCl}_{2}$ or $\mathrm{CuSO}_{4}$. With $\mathrm{EG}$, the intermediate compounds $\mathrm{Cu}_{3}(\mathrm{OAc})_{2}\left(\mathrm{C}_{2} \mathrm{H}_{4} \mathrm{O}_{2}\right)_{2}, \mathrm{Cu}\left(\mathrm{C}_{2} \mathrm{H}_{4} \mathrm{O}_{2}\right)$, and $\mathrm{Cu}_{2} \mathrm{O}$ were observed during the reaction. Experiments with higher glycol ethers show that increasing the polyol chain length decreases the stability of alkoxides und therefore enhances the stability range of $\mathrm{Cu}_{2} \mathrm{O}$. In the case of TEG, no alkoxide compound but phase-pure $\mathrm{Cu}_{2} \mathrm{O}$ was detected in a very wide temperature range. The formation of $\mathrm{Cu}_{2} \mathrm{O}$ or alkoxide compounds reduces the $\mathrm{Cu}^{2+}$ concentration in the reaction solution and therefore leads to a small number of nuclei resulting in micro- rather than nano-sized copper particles. Under alkaline reaction conditions, e.g. by addition of $\mathrm{NaOH}$, the lowest reduction temperature and the smallest particle sizes are achieved due to a higher $\mathrm{Cu}^{2+}$ concentration prior to nucleation.

This study shows, that the anion-dependent reduction behaviour of copper in polyols is similar to the less noble metals cobalt and nickel, although the occurrence of the stable oxidation state $+\mathrm{I}$ is a peculiarity of the copper system. Less noble metals should be treated under alkaline conditions to ensure a complete reduction at the lowest possible temperature.

\section{Experimental}

\section{Chemicals}

Freshly supplied polyols were used as received: ethylene glycol (Fluka, 99.5\%), diethylene glycol (Aldrich, 99\%), triethylene glycol (Alfa Aesar, 99\%), and tetraethylene glycol (Acros, 99.5\%). Hydrated copper(II) salts were used for all syntheses: $\mathrm{CuCl}_{2} \cdot 2 \mathrm{H}_{2} \mathrm{O}$ (Aldrich, 99\%), $\mathrm{CuSO}_{4} \cdot 5 \mathrm{H}_{2} \mathrm{O}$ (Aldrich, 99\%), $\mathrm{Cu}\left(\mathrm{NO}_{3}\right)_{2} \cdot 2.5 \mathrm{H}_{2} \mathrm{O}(\mathrm{ABCR}, 99.5 \%), \mathrm{Cu}(\mathrm{OAc})_{2} \cdot \mathrm{H}_{2} \mathrm{O}$ (Aldrich, 99\%). $\mathrm{Cu}(\mathrm{OH})_{2}$ was prepared by precipitation of an aqueous solution of $\mathrm{CuSO}_{4} \cdot 5 \mathrm{H}_{2} \mathrm{O}$ with 2 eq. of $\mathrm{NaOH}$. The light blue powder was filtrated, washed several times with water and ethanol, and dried under vacuum at ambient temperature overnight. For some experiments, solutions of $\mathrm{NaOH}$ (Grüssing, 99\%), $\mathrm{NaOAc} \cdot 3 \mathrm{H}_{2} \mathrm{O}$ (Grüssing, 99.5\%), or $\mathrm{NaCl}$ (VWR Prolabo, 99.9\%) in $\mathrm{EG}$ with a concentration of $1 \mathrm{~mol} \mathrm{l}^{-1}$ were used. 


\section{Synthesis}

For each experiment, the respective copper(II) compound $(0.5 \mathrm{mmol})$ was mixed with $5 \mathrm{ml}$ of the polyol in a flask equipped with a magnetic stirring bar and a reflux condenser. In some experiments a specified amount of $\mathrm{NaOH}$, $\mathrm{NaOAc} \cdot 3 \mathrm{H}_{2} \mathrm{O}$, or $\mathrm{NaCl}$ solution was added, maintaining the total volume of $5 \mathrm{ml}$. Heating was performed with a CEM Discover-SP microwave device under open vessel conditions. The reaction temperature was controlled with the in-built infrared sensor. The mixture was heated to the desired temperature in $3 \mathrm{~min}$, annealed for $30 \mathrm{~min}$, and rapidly cooled down to $60{ }^{\circ} \mathrm{C}$ with compressed air. The solid products were collected by centrifugation, repeatedly washed with ethanol, and finally dried under vacuum at ambient temperature.

\section{Powder characterisation}

Powder X-ray diffraction (PXRD) patterns were collected with a transmission-geometry diffractometer Stadi P (Stoe) equipped with a Mythen $1 \mathrm{~K}$ detector (Dectris) using Ge(111)-monochromated $\mathrm{Cu}-\mathrm{K}_{\alpha 1}$ radiation $(\lambda=154.056 \mathrm{pm})$. The powder samples were placed between two layers of adhesive tape. Crystallographic data from the Inorganic Crystal Structure Database was used to calculate reference powder patterns for $\mathrm{Cu}$ (CSD 627114), $\mathrm{Cu}_{2} \mathrm{O}$ (CSD 180846) and $\mathrm{Cu}(\mathrm{OH})_{2}$ (CSD 68459). Fourier-transform infrared (FT-IR) spectra were measured with a Vertex 80 (Bruker) spectrometer in attenuated total reflectance mode in the wavelength range $4000-500 \mathrm{~cm}^{-1}$. Scanning electron microscopy (SEM) was performed using a SU8020 electron microscope (Hitachi) equipped with a tripledetector system for secondary and low-energy backscattered electrons with an acceleration voltage of $3 \mathrm{kV}$. DTA-TG curves were recorded with a STA 409 thermal analyser (Netzsch). The samples were heated under air in an alumina crucible with a rate of $5 \mathrm{~K} \mathrm{~min}^{-1}$ up to $600{ }^{\circ} \mathrm{C}$. Elemental analysis was carried out with a Vario MICRO cube CHNS analyser (Elementar). Magnetisation measurements were conducted with a Heliumcooled vibrating sample magnetometer (Cryogenic) in DC mode in the range $2-300 \mathrm{~K}$.

\section{Single-crystal X-ray crystallography}

A suitable single crystal of $\mathrm{Cu}_{3}(\mathrm{OAc})_{2}\left(\mathrm{C}_{2} \mathrm{H}_{4} \mathrm{O}_{2}\right)_{2}$ was mounted on the tip of a glass fibre and cooled to $100 \mathrm{~K}$ under flowing nitrogen gas. Intensity data were collected with a four-circle diffractometer Kappa Apex2 (Bruker) equipped with a CCDdetector using graphite-monochromated $\mathrm{Mo}-\mathrm{K}_{\alpha}$ radiation $(\lambda=$ $71.073 \mathrm{pm}$ ). Data were corrected for Lorentz and polarisation factors, ${ }^{36}$ and multi-scan absorption correction ${ }^{37}$ was applied. The structure was solved using SHELXT intrinsic phasing ${ }^{38}$ and refined with full-matrix least-squares based on $F_{\mathrm{o}}{ }^{2}$ with SHELXL $^{39}$ using the OLEX2 $2^{40}$ program package. Refinement included anisotropic displacement parameters for all nonhydrogen atoms. Hydrogen atoms were refined with riding coordinates and displacement parameters. Graphics were developed with Diamond. ${ }^{41}$ The crystal structure data have been deposited at the Cambridge Crystallographic Data Centre, deposit number 1857785. $\dagger$

\section{Conflicts of interest}

There are no conflicts to declare.

\section{Acknowledgements}

We thank Philipp Lange for elemental analysis, Dr Ilka Kuhnert for DTA-TG measurements, Dr Martin Kaiser for assistance with the single-crystal measurement, and Dr Jens Hunger for measuring magnetic data and helpful discussions. Open Access funding provided by the Max Planck Society.

\section{Notes and references}

1 M. Figlarz, F. Fiévet and J.-P. Lagier, Process for the Reduction of Metallic Compounds by Polyols, and Metallic Powders Obtained by This Process, US 4539041A, 1985.

2 F. Fiévet, J. P. Lagier, B. Blin, B. Beaudoin and M. Figlarz, Solid State Ionics, 1989, 32-33, 198-205.

3 F. Fiévet, J.-P. Lagier and M. Figlarz, MRS Bull., 1989, 14, 29-34.

4 H. Dong, Y.-C. Chen and C. Feldmann, Green Chem., 2015, 17, 4107-4132.

5 F. Bonet, C. Guéry, D. Guyomard, R. Herrera Urbina, K. Tekaia-Elhsissen and J.-M. Tarascon, Int. J. Inorg. Mater., 1999, 1, 47-51.

6 F. Bonet, C. Guéry, D. Guyomard, R. Herrera Urbina, K. Tekaia-Elhsissen and J.-M. Tarascon, Solid State Ionics, 1999, 126, 337-348.

7 M. Heise, J.-H. Chang, R. Schönemann, T. Herrmannsdörfer, J. Wosnitza and M. Ruck, Chem. Mater., 2014, 26, 5640-5646.

8 A. J. Biacchi and R. E. Schaak, ACS Nano, 2011, 5, 80898099.

9 G. Viau, F. Fiévet-Vincent and F. Fiévet, Solid State Ionics, 1996, 84, 259-270.

10 T. Matsumoto, K. Takahashi, K. Kitagishi, K. Shinoda, J. L. C. Huaman, J.-Y. Piquemal and B. Jeyadevan, New J. Chem., 2015, 39, 5008-5018.

11 K. Takahashi, S. Yokoyama, T. Matsumoto, J. L. C. Huaman, H. Kaneko, J.-Y. Piquemal, H. Miyamura and J. Balachandran, New J. Chem., 2016, 40, 8632-8642.

12 P. Lignier, R. Bellabarba and R. P. Tooze, Chem. Soc. Rev., 2012, 41, 1708-1720.

13 F. Fiévet, F. Fiévet-Vincent, J.-P. Lagier, B. Dumont and M. Figlarz, J. Mater. Chem., 1993, 3, 627-632.

14 J. Sun, Y. Jing, Y. Jia, M. Tillard and C. Belin, Mater. Lett., 2005, 59, 3933-3936.

15 A. Cao, J. D. Monnell, C. Matranga, J. Wu, L. Cao and D. Gao, J. Phys. Chem. C, 2007, 111, 18624-18628.

16 A. Anžlovar, Z. C. Orel and M. Žigon, J. Nanosci. Nanotechnol., 2008, 8, 3516-3525. 
17 S. E. Okan and P. S. Salmon, Mol. Phys., 1995, 85, 981-998.

18 K. J. Carroll, J. U. Reveles, M. D. Shultz, S. N. Khanna and E. E. Carpenter, J. Phys. Chem. C, 2011, 115, 2656-2664.

19 CRC Handbook of Chemistry and Physics, ed. W. M. Haynes, CRC Press, Boca Raton, Florida, USA, 2016.

20 Z. C. Orel, E. Matijević and D. V. Goia, J. Mater. Res., 2003, 18, 1017-1022.

21 Y. Meng and A. J. Bard, Anal. Chem., 2015, 87, 3498-3504.

22 C. Feldmann and H.-O. Jungk, Angew. Chem., Int. Ed., 2001, 40, 359-362.

23 G. G. C. Arizaga, K. G. Satyanarayana and F. Wypych, Solid State Ionics, 2007, 178, 1143-1162.

24 H. R. Oswald, A. Reller, H. W. Schmalle and E. Dubler, Acta Crystallogr., Sect. C: Cryst. Struct. Commun., 1990, 46, 22792284.

25 S. Švarcová, M. Klementová, P. Bezdička, W. Łasocha, M. Dušek and D. Hradil, Cryst. Res. Technol., 2011, 46, 1051-1057.

26 N. Chakroune, G. Viau, S. Ammar, N. Jouini, P. Gredin, M. J. Vaulay and F. Fiévet, New J. Chem., 2005, 29, 355-361.

27 K. Tekaia-Elhsissen, A. Delahaye-Vidal, G. Nowogrocki and M. Figlarz, C. R. Acad. Sci., Ser. II, 1989, 309, 469-472.

28 Y.-Y. H. Chao and D. R. Kearns, J. Phys. Chem., 1977, 81, 666-668.

29 N. Habermann, G. Jung, M. Klaassen and P. Klüfers, Chem. Ber., 1992, 125, 809-814.
30 C. P. Love, C. C. Torardi and C. J. Page, Inorg. Chem., 1992, 31, 1784-1788.

31 A. R. Pico, C. S. Houk, T. J. R. Weakley and C. J. Page, Inorg. Chim. Acta, 1997, 258, 155-160.

32 J. H. Rivers, K. J. Carroll, R. A. Jones and E. E. Carpenter, Acta Crystallogr., Sect. C: Cryst. Struct. Commun., 2010, 66, $\mathrm{m} 83-\mathrm{m} 85$.

33 O. C. Gagné and F. C. Hawthorne, Acta Crystallogr., Sect. B: Struct. Sci., Cryst. Eng. Mater., 2015, 71, 562-578.

34 S. M. Biros, B. M. Bridgewater, A. Villeges-Estrada, J. M. Tanski and G. Parkin, Inorg. Chem., 2002, 41, 40514057.

35 L. Poul, N. Jouini and F. Fiévet, Z. Kristallogr., 1998, 213, 416-418.

36 SAINT+: Area-Detector Integration Software, Version 8.34A, Bruker AXS Inc., Madison, Wisconsin, USA, 2013.

37 SADABS: Area-Detector Absorption Correction, Version 2014/4, Bruker AXS Inc., Madison, Wisconsin, USA, 2014.

38 G. M. Sheldrick, Acta Crystallogr., Sect. A: Found. Adv., 2015, 71, 3-8.

39 G. M. Sheldrick, Acta Crystallogr., Sect. C: Struct. Chem., 2015, 71, 3-8.

40 O. V. Dolomanov, L. J. Bourhis, R. J. Gildea, J. A. K. Howard and H. Puschmann, J. Appl. Crystallogr., 2009, 42, 339-341.

41 K. Brandenburg, Diamond 4: Crystal and Molecular Structure Visualization, Crystal Impact GbR, Bonn, Germany, 2017. 